\title{
Periódicos eletrônicos: considerações relativas à aceitação deste recurso pelos usuários*
}

\section{G uilherme A taíde D ias}

Bacharel em C iência da Computação - U niversidade Federal da Paraíba - 1990. M estre em A dministração - C entral C onnecticut State U niversity, U SA -1996. D outorando em Ciência da Informação - U niversidade de São Paulo, ECA/U SP. E-mail: guilhermeataide@ aol.com

\section{Resumo}

Este artigo apresenta algumas reflexões sobre a aceitação de periódicos eletrônicos disponibilizados na World Wide Web. Assuntos que freqüentemente são ignorados durante a elaboração dos mesmos são discutidos. Citam-se como exemplo alguns periódicos científicos eletrônicos brasileiros na área da ciência da informação. Analisam-se também algumas barreiras tecnológicas que impedem o uso mais amplo e irrestrito deste recurso.

\section{Palavras-chave}

Periódicos eletrônicos; Usabilidade; Novas tecnologias.

\section{Electronic journals: issues on the user's acceptance of this resource}

\begin{abstract}
This article presents some insights on the user's acceptance of electronic journals made available in the World Wide Web. Issues that are frequently ignored during the project of electronic journals are discussed. As an example, some electronic Brazilian journals in the field of information science are cited. Some technological barriers which encumber a wider and unrestricted use of the electronic journals are also analyzed.
\end{abstract}

\section{Keywords}

Electronic journals; Usability; New technologies.

\section{INT RO DUÇÃO}

A introdução contínua de novas tecnologias, no dia-adiado ser humano, produz alterações naforma de execução do trabal ho eprocessos relacionados. Podemos constatar como exemplo representativo desta afirmação a evolução das tecnologias relacionadas ao processo dedifusão da escrita. Vejamos a seguir, de maneira resumida, al gumas das etapas destaevolução. Retornando aum passado longínquo naantigüidade, verificamos como poucos eprivilegiados leitores tinham acesso ao texto escrito. Esse texto estava muito provavelmente materializado em rolos feitos de couro animal, que, como tal, para ser lido precisava ser desenrolado com a utilização das duas mãos do leitor, atrapalhando a realização dealguma outra tarefa que necessitasse da utilização deste membro. V isualizando agora o século IV da era cristã, constataremos o surgimento deum novo suporte para a difusão do texto escrito que se impõe de forma incisiva. Este suporte chamava-se códex, que nada mais era do queum livro, constituído de fol has dobradas, reunidas e encadernadas, que veio suplantar de forma indiscutível os rolos até então predominantes. A utilização deste novo suportetrouxeuma série de benefícios atéentão difíceis deserem realizados, tais como a possibilidade de seescrever durante a atividade de leitura. 0 s dispositivos inerentes ao códex transformaram de forma radical a utilização dos textos (C hartier, 2002).

Chartier (2002, p.106) afirmaque:

“A invenção da página, as localizações garantidas pela paginação e pela indexação, a nova rel ação estabel ecida entre obra e objeto que éo suporte de sua transmissão tornaram possível uma relação inédita entre o leitor e seuslivros".

$M$ ais recentemente, naúltima metade do século $X X$, testemunhamosa introdução do meio eletrônico como um novo suporteà difusão daescrita. Estemeio estáalterando deforma progressivaa maneiracomo interagimoscom o texto escrito. 0 meio eletrônico possibilita autilização dos avanços introduzidos pelos livros além deesten-

*Este artigo faz parte da tese de doutorado em C iência da I nformação do autor, que tem como orientadora a doutora D inah Población 


\section{Periódicos el etrônicos: considerações relativas à aceitação deste recurso pelos usuários}

der estas possibilidades graças às características intrínsecas a este meio que seriam impossíveis de serem implementadas da maneiratradicional.

A nalisaremos a seguir al guns tópicos relacionados às publicações eletrônicas que contribuem para dificultar umaadoção mais ampladesterecurso. Enfatizaremos mais especificamente os periódicos científicos eletrônicos disponibilizados em sites daW orld WideWeb, queconstituem um exemplo específico da utilização do meio eletrônico na divulgação de informações.

Periódicos eletrônicos: o novo ou aadaptação deum padrão existente?

A utilização inadequada de uma nova tecnologia, como conseqüência de uma reduzida compreensão dos recursos que a mesma pode proporcionar, contribui para que ela não seja utilizada de forma ampla. J ohnson (2001, p.107) ajuda a validar esteraciocínio anterior afirmando o seguinte: "A s novas tecnologias, quando nascem, são sempremal compreendidas, muitas vezes pelos queestão mais próximos delas".

$\mathrm{H}$ istoricamentenós temos exemplos detecnologias que tiveram originariamente um uso diferente do que conhecemos hoje. Johnson (2001) explica que, quando da invenção do fonógrafo por Thomas Edison, o mesmo pensou na utilização deste equipamento como um gravador deconversas telefônicas, enão como um reprodutor demúsica. 0 tempo mostrou o equívoco deEdison, pois as pessoas não estavam interessadas na gravação do que falavam ao telefone. Este raciocínio nos leva a refletir: será que os usuários poderiam achar, ou sugerir novas formas de uso para os periódicos científicos el etrônicos, diferentes das pensadas pelos editores, especialistas em mídia ou analistas de sistemas? A creditamos quesim, ea utilização plena destes periódicos passa pela incorporação no desenvolvimento dos mesmos das funcionalidades descobertas e requeridas pelas pessoas que os utilizam.

N o momento em que fazemos acesso a al guma revista científica eletrônica, disponibilizada em algum siteda Web, não é difícil constatar que a vasta maioria das mesmas não faz bom uso dos recursos passíveis de implementação para o padrão Web. 0 queencontramos na maior parte dos casos éa meratranscrição de periódicosjá existentes de forma impressa para o meio eletrônico, e mesmo os periódicos quejá nasceram no mundo eletrônico, sem nunca terem nenhum "ancestral" no formato impresso, não implementam as possibilidades inerentes ao meio eletrônico deforma satisfatória.
Entendemos que o meio el etrônico, por representar um novo paradigmana disseminação de informações, deveria ser explorado detal formaque fossefeito uso integral desuas possibilidades. Q uestionamos ainda se autilização pura esimples do meio eletrônico como uma mera transcrição do meio impresso não seria um obstáculo para uma utilização mais ampla dos periódicos científicoseletrônicos.

U ma interessante colocação sobre o meio eletrônico é feitapor C hartier (2002, p.113) e nos faz refletir sobre seu pensamento:

"A revolução do texto eletrônico* é, de fato, ao mesmo tempo, uma revolução da técnica de produção dos textos, uma revolução do suporte do escrito e uma revolução das práticas deleitura".

C onsiderando a citação acima, podemos sugerir que os procedimentos voltados paraa produção, suportee práticas de leituras, associados ao texto eletrônico, devem ser distintos de procedimentos similares associados ao texto impresso, de outra formanão poderemos considerar que a revolução do texto eletrônico esteja completa em todo o seu potencial. De uma maneira mais simplificada: se um texto vai ser disponibilizado no meio eletrônico, sua produção deveria ser el aborada com o auxílio de aplicativos utilizados para o processamento eletrônico detextos, de outra maneira perderíamos aflexibilidade de edição associada a estetipo de ferramenta, bem como a necessidade de uma etapa a mais para a digitalização do texto manuscrito; da mesmaforma, se um texto está disponibilizado de forma eletrônica, nos pareceque o mesmo deveriaser lido com o auxílio de um suporte tecnológico el etrônico, dispensando a impressão em papel, o quenem sempreacontece.

A presentaremos, a seguir, al guns tópicos associados aos periódicos científicos el etrônicos que devem ser considerados para que a revolução do texto eletrônico seja concretizada. A lguns destes tópicos seriam: o uso do hipertexto, a utilização de ferramentas de indexação e busca e a adequação de diferentes formatos de texto ao meio eletrônico.

${ }^{*}$ Grifo nosso. 


\section{G uilherme A taíde D ias}

U ma das possibilidades mais interessantes disponibilizadas pelaW eb é a utilização do hipertexto. A arquitetura da Web está fundada na utilização do mesmo por meio da exploração de suas trilhas. C ontudo, verificamos queo uso do hipertexto nos documentos publicados na Web émuitas vezes negligenciado. 0 s padrões encontrados são de textos lineares, à semel hança de seus primos impressos, tal situação distancia os textos encontrados naWeb das idéias seminais de Vannevar Bush, feitas na primeira metade do século $X X$ quando dadescrição de seu invento, o M emex, queem muito seassemeIhava ao que encontramos hoje quando navegamos na trilhas daWeb.

Johnson (2001, p.95) contribui para qualificar a idéia acimaapresentadaafirmando que:

"Entreos textos baseados naWeb preponderam delonge os francamente lineares. Q uase todas as matérias jornalísticas são peças únicas, unidimensionais, artigos que seriam exatamenteos mesmos se fossem compostos de tinta e papel em vez de zeros e uns (muitos deles, é claro, são simplesmente versões digitais de originais impressos)."

A utilização dos recursos inerentes ao hipertexto oferece novas oportunidades de cognição que suplementam as of erecidas pelos artigos disponibilizados em papel de forma estritamentelinear ( $M$ arcondes, 2001). Segundo M arcuschi (1999), a natureza do hipertexto está associada a diversas características, dentre as quais apresentamosalgumas:

- Não-Linearidade- Estaéumadas características centrais do hipertexto, está relacionada com aflexibilidade de se percorrerem as diversas redes navegáveis de um hipertexto. 0 usuário tem a autonomia de percorrer 0 caminho que achar mais adequado e da maneira que melhor Ihe convier, não existindo a priori um caminho único efixo aser seguido;

- A cessibilidade ilimitada- 0 hipertexto permiteque sejam acessados os mais diversos tipos e fontes, não importando se el as são artigos de periódicos, materiais de referência, obras literárias ou qual quer outra coisa;

- M ultissemiose - Esta característica está relacionada com a possibilidade que o hipertexto tem de interconectar, de forma simultânea e integrada, a linguagem verbal ea linguagem não-verbal;
- Interatividade - relaciona-se com a característica de uma ação qual quer gerar umareação em tempo real como respostaà ação anterior. C onsiderando aW orld WideWeb como um exemplo de hipertexto, verificamos que ao se selecionar uma determinada ligação ( link) somos imediatamente remetidos a uma outra instância;

- Virtualidade- o hipertexto éum fenômeno que existedeformaúnica exclusivano espaço virtual; não existe hipertexto no mundo real e concreto que nós habitamos. A Iguns podem afirmar que existe hipertexto no mundo real e, também, que desenhos em uma página de um artigo de periódico com referências para uma explicação nas suas margens seria um exemplo de hipertexto no mundo real ( preferimos não relevar esta hipótese).

A utilização do hipertexto em um artigo científico, entre outras coisas, pode servir como fonte de referência, facilitando a leitura do mesmo. Vejamos, como exemplo, um artigo publicado em uma revista el etrônica na área de ciência da informação que trate da utilização de criptografia, equeao longo desteartigo existam referências à máquina Enigma*. É possível que a referência à máquina Enigma não faça sentido para al gum leitor, ou queo mesmo, emboraconhecendo o referido termo, desejemais informações sobre o assunto. A simples utilização de uma trilha que ligasse a pal avra E nigma a uma página com informações sobre a mesma atenderia esta necessidade informacional. M eadows (1999, p.36) complementa a idéia afirmando que:

“...o leiaute clássico darevista impressa pode ser reproduzido facilmentenatela (levando em conta os diferentesformatos epossibilidades dapágina impressae datela), porém o computador of erece recursos adicionais. U m deles diz respeito às referências apensas aum artigo. $U$ ma referênciaem um artigo impresso que remeteparaoutro artigo ou livro implicauma busca bibliográfica separada, caso se queira consultar o trabalho citado. $\mathrm{N}$ o caso da revista eletrônica, ela pode ser organizada detal forma que outros materiais citados no texto de um artigo possam ser trazidos imediatamente à tela com o apertar de um botão."

* M áquina alemã projetada para cifrar códigos, utilizada ao longo da II Guerra Mundial. 
A própria indústria que lucra com a produção e comercialização de produtos de software para a navegação naWeb também não contribuiu para o desenvolvimento do hipertexto, ainda sobre este assunto J ohnson (2001, p. 83) relata que:

“... quase na metade de 1996, a N etscape e a M icrosoft lançaram novas versões de seus respectivos navegadores, quebrando uma espécie de recorde informal paraos mais rápidos upgrades de softwarenahistória. A acreditar nos press-releases que as acompanharam, essas duas versões somadas introduziam mais de uma centena de novas características. $\mathrm{H}$ avia upgrades para suporte de J ava, novostipos de animação, plug-ins de som, filtros de e-mail e assim por diante. M as nenhuma dessas novas características- nem uma - aperfeiçoava o gesto básico declicar em um link detexto. A verdadeira pedra angular da World W ideWeb havia sido completamenteignorada sob uma nevasca de outrosacréscimos gratuitos" ".

E mbora devendo inovações nos navegadores que privilegiem a utilização do hipertexto, a indústria disponibiliza no mercado uma variedade de ferramentas voltadas para a elaboração de hipertextos pelo usuário final, desde processadores de textos bastante populares como o M icrosoft W ord** até ferramentas mais simples paraa elaboração depáginas $\mathrm{H} \mathrm{TM} \mathrm{L,} \mathrm{tais} \mathrm{como} \mathrm{o} \mathrm{C} \mathrm{omposer,}$ que faz parte do navegador $\mathrm{N}$ etscape.

Baseado no fato da existência e do fácil acesso a ferramentas para a elaboração de hipertexto, podemos questionar se os autores de artigos científicos estarão dispostos a utilizar as mesmas na elaboração de seus artigos. A simples existência de ferramentas não garante de maneira al guma asuautilização.

D iversos motivos podem ser levantados para que um autor não inclua hipertexto em um artigo a ser disponibilizado em um periódico científico el etrônico, entreeles, o sentimento de quetal procedimento édesnecessário; a existência de barreiras culturais sedimentadas ao longo dos anos pelo ato de realizar tarefas sempre de uma mesmamaneira, atéa dificuldadeem trabal har com os produtos desoftwarepróprios para o uso do hipertexto. Produtos estes, que, emboratenham evoluído ao longo dos anos, com atransição da interface do padrão texto parao padrão gráfico, ainda apresentam

\footnotetext{
${ }^{*}$ G rifo nosso.

${ }^{* *} \mathrm{U} \mathrm{m}$ texto elaborado com o Microsoft Word pode ser facilmente transformado em H TML para a publicação na World Wide Web.
}

barreiras de uso para os usuários sem a devidafamiliaridadecom autilização dos mesmos.

A lém do hipertexto, um outro recurso fundamental que deveria estar sempre disponível nos sites quehospedam periódicos científicos eletrônicos seriam as ferramentas de indexação e busca. I nfelizmente, mesmo sen do evidente que pesquisar de forma manual determinado assunto, entre diversos números de periódicos, não seja exatamenteumatarefa produtiva, muitas das vezes esta éa situação encontrada. C onsideramos que, para ter um periódico científico eletrônico que justifique o nome "eletrônico", o mesmo deveria também fazer uso deste recurso.

A rtigos de periódicos sempre foram indexados e pesquisados demaneira convencional, contudo o meio eletrônico oferece uma flexibilidade até então difícil de ser reproduzidano meio impresso, sejapelabuscadeforma praticamente instantânea de qual quer palavra isolada contida em um artigo de periódico, seja pelo uso de expressões boleanas bastanteelaboradas.

Se o meio eletrônico facilitou o trabalho de busca nos conteúdos para os usuários, também, da mesma forma ajudou bastante o pessoal técnico de retaguarda, envolvido com a indexação de artigos de periódicos para posterior consulta, pois a maior parte do trabalho repetitivo inerente à indexação de conteúdos começa a ser feito por um sistema automatizado. A ssim, uma vez o software configurado, o processo de indexação éfeito de forma automática, dispensando praticamente qualquer intervenção humanano processo.

É importantenão deixar demencionar que, emboraos processos de indexação ebusca automática sejam feitos rapidamenteedispensem o uso intensivo de mão-de-obra, eles apresentam deficiências pela baixa qualidade da indexação e pelo grandenúmero de informações sem relevância recuperadas quando da execução de uma busca, oferecendo altarevocação, contudo com baixa precisão ( $M$ arcondes, 2001). C omo todatecnologia, as ferramentas deindexação ebusca agregaram, com o passar do tempo, novos recursos, esuas deficiências vão sendo paulatinamente suplantadas. D esta forma, é de se esperar que ocorram melhoras nos seusíndices de precisão. 
D os periódicos científicos eletrônicos brasileiros na área da ciência da informação, apenas al guns fazem uso deferramentas automáticas de indexação e busca, dos quais podemosmencionar os seguintes:

Informação \& Sociedade: E sudos: faz uso de uma ferramenta para indexação e busca ao conteúdo dos artigos. O softwareutilizado por esteperiódico éo htdig* cujo modelo de licenciamento é baseado no paradigma do software livre ( free software). N o caso do periódico I nformação \& Sociedade: E studos, 0 htdig está configurado paraindexar 0 conteúdo dos resumos associados acada artigo de periódico, o nome dos artigos e os respectivos autores. $C$ om relação à ferramenta de busca associada a este periódico, constatamos que a mesma com grande freqüência estáfora do ar, aumentando assim deforma considerável o tempo gasto na busca de informações disponibilizadas pelo periódico (figura 1);

C iência da Informação: possui uma ferramenta de busca para todo o site (www.ibict.br) onde estáhospedado 0 periódico. A creditamos que, por questões de usabilidade, a busca aos artigos do periódico deveria ser separada da busca do siteno I bict como um todo, permitido desta forma melhorar a precisão das informações retornadas. Realizamos pesquisas com al gumas palavras-chavee obtivemos referências para diversos pontos do sitedo I bict que não tinhanenhumarelação com o periódico (figura2);

\section{FIGURA 1}

\section{Tela ferramenta de busca da revista I nformação \& Sociedade: Estudos}

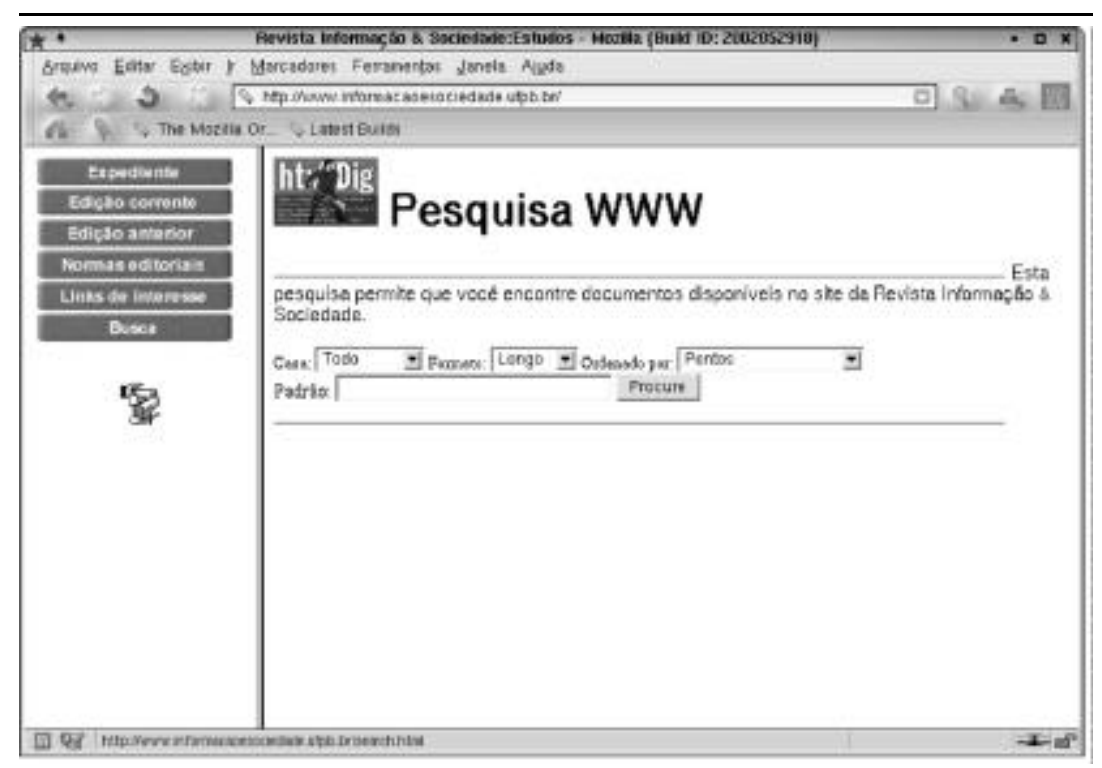

FIGURA 2

Tela ferramenta de busca da revista C iência da I nformação

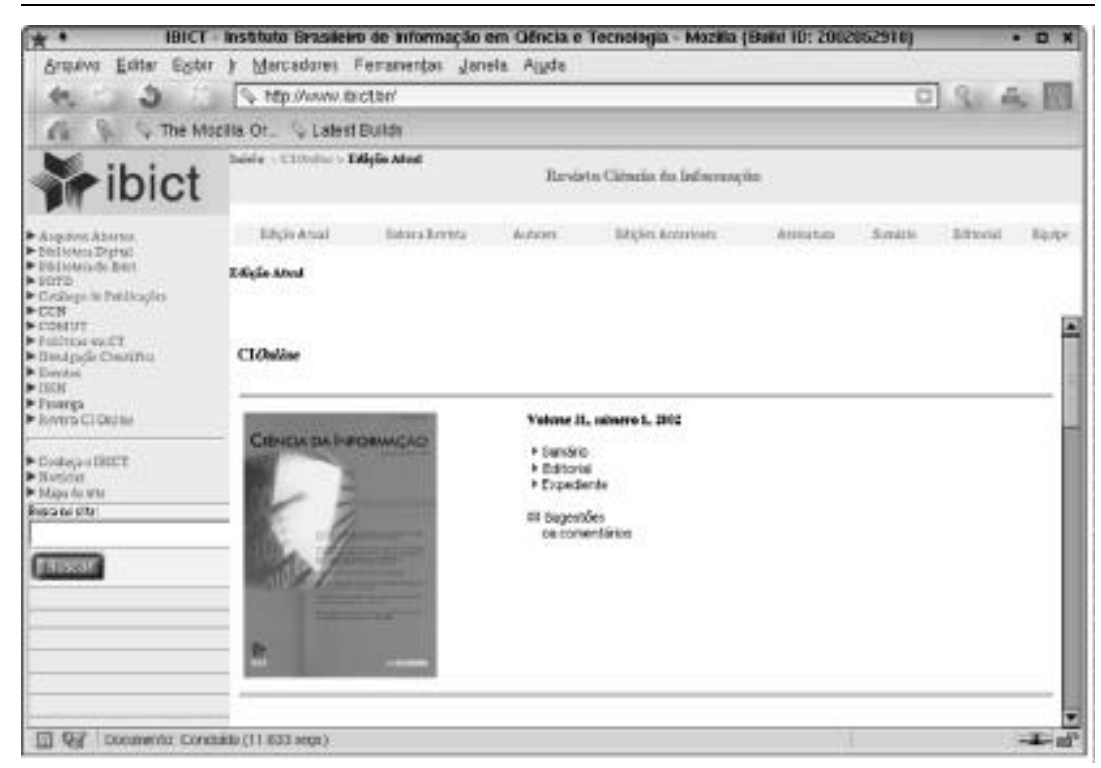

* Mais informações sobre o htdig podem ser obtidas em: http: // www.htdig.org. 
Perspectivasem C iência da Informação: embora não contenha os artigos integrais para consultaon-line, estando os artigos disponíveis apenas em formato papel, é feito uso de uma ferramenta para a busca de informações. $N$ este caso, uma ferramenta chamada G reenstone*, que é um produto de software utilizado para a construção e distribuição de coleções de bibliotecas digitais. $0 \mathrm{G}$ reenstoneé produzido pelo $\mathrm{N}$ ew Zealand D igital Library Project na U niversidade de Waikato, em cooperação com aU nesco (igura3).

Podemos, ainda, citar como exemplo de periódicos científicos eletrônicos na área da ciência da informação que não disponibilizam umaferramenta debusca para os seus usuários os periódicos

D ataG ramaZ ero e Encontros Bibli: Revista de biblioteconomia eC iência da I nformação.

A pouca utilização do hipertexto e de ferramentas de buscanosfaz indagar seatecnologiaestásendo utilizada de forma equivocada quando consideramos os periódicos científicos el etrônicos. Este eoutros pontos nos farão refletir sobre a mesma situação.

\section{Periódicos eletrônicos: usos e desusos}

N os primórdios desuautilização, os computadores eram essencial mentemáquinas "devoradoras denúmeros", utilizadas nas mais diversas atividades que demandavam processamento numérico, não demorando muito para também serem utilizados em atividades que necessitassem de processamento alfabético. 0 processamento de fontes de informações secundárias como os guias dacomunicação científica, tais como os resumos eosíndices, são um bom exemplo disto, enos remetem à década de 60 do século XX (M eadows, 1999).

0 processamento eletrônico defontes de informações secundárias facilitou, de maneira considerável, alocalização deinformações com aajudada crescentecapacidade de armazenamento e busca dos dispositivos computacionais e o desenvolvimento de programas aplicativos com mais recursos parao usuário final.
A companhando o processamento eletrônico de fontes de informações secundárias e seguindo o contínuo desenvolvimento tecnológico, passamos a nos deparar também com o uso do meio eletrônico no processamento de fontes de informações primárias, dentreas quais nos interessam, nesteestudo, apenas os periódicos científicos. Com relação aos diferentes tipos de informações que podem ser de valia para os pesquisadores, M eadows (1999, p.34) afirmaque:

"D o ponto de vista da comunicação científica, entretanto, o meio eletrônico só se torna de fato interessante quando pode processar todos os tipos de informação que interessam aos pesquisadores".

M eadows (1999) comenta ainda que a transição daliteratura primária para o formato eletrônico não está se concretizando da maneira esperada, e, segundo o autor, uma das causas destefenômeno seriam os recursos inerentes ao próprio computador.

A nalisaremos, a seguir, al guns aspectos relacionados aos periódicos científicos eletrônicos que, se adequadamenteentendidos pelos editores, podem contribuir deforma decisiva parauma compreensão das razões quelevam os usuários autilizar ou não os mesmos.

\footnotetext{
${ }^{*}$ M ais informações sobre o G reenstone podem ser obtidas em http:// www.greenstone.org. 


\section{G uilherme A taíde D ias}

Entendemos que, de uma forma geral, o usuário de um periódico científico eletrônico podefazer uso do mesmo de duas maneiras distintas:

1. o usuário, deposse do endereço do periódico eletrônico, acessa a informação desejada efaz a leitura do mesmo em terminal de vídeo, fazendo uso do hipertexto e das ferramentas de busca semprequenecessário. C onsideramos como terminal de vídeo um monitor de raios catódicos, uma tela LCD e produtos equivalentes que não produzem uma saída deformafísica;

2. o usuário, de posse do endereço do periódico eletrônico, acessa a informação desejada esolicita a impressão do conteúdo em um dispositivo de impressão tal como uma impressora jato detinta oulaser parauma posterior leitura.

A creditamos quegrandequantidade de usuáriosfaz uso dos periódicos el etrônicos dasegundamaneira apresentada, o que, neste caso, significa que ossites hospedeiros dos mesmos estão funcionando como um repositório eletrônico deinformações. 0 ato do usuário ao ler o periódico nestecaso é equivalente ao de um usuário que vai a uma biblioteca e solicita uma versão impressa do mesmo. Estasituação, aqui apresentada, faz-nos indagar se neste caso o usuário estaria realmente fazendo uso de toda funcionalidade disponibilizadapelo periódico eletrônico - pode ser que neste caso não estejam implementados o hipertexto eferramentas de busca- ou estaria fazendo uso do site que o hospeda apenas como uma plataforma para a distribuição de cópias de artigos convertidos para o formato digital.

0 ato de apenas imprimir 0 artigo, para uma posterior leitura, não desqualifica o meio eletrônico, apenas afirmaqueos usuários encontraram uma aplicação queacham mais adequada parao periódico dito "eletrônico". William Gibson em N euromancer, citado por J ohnson (2001, p.108), diz que: "A rua descobreseus própriosusos para as coisas- usosqueosfabricantesnunca imaginaram".

O cenário acima descrito ésem dúvidas uma aplicação interessante eválida da tecnologia, contudo vejamosalgumas razões que afastam os usuários de utilizarem os periódicos eletrônicos daprimeira maneira apresentada.

M eadows (1999, p.153) explica que existe uma dificuldade por parte dos usuários em internal izar informações a partir datela do computador. Esta dificuldadeémaior quando consideramos os livros eletrônicos devido ao seu maior volume è̀ sua natureza seqüencial. A s revistas eletrônicas representam um obstáculo menor para asua apreensão, pois os textos dos artigos de periódicos não possuem o mesmo volume dos textos contidos nos livros, o que facilita a sua leitura. M esmo assim, conhecemos usuários quesimplesmentefazem umabuscano periódico por um determinado artigo eo imprimem, conformeapresentado anteriormente.

A inda, deacordo com M eadows (1999, p.153), podemos afirmar queas obras de referência, tais como dicionários e enciclopédias, adequaram-se de maneira mais satisfatóriaao meio eletrônico, pois, em contraponto aos livros e às revistas el etrônicas, as consultas a obras de referência estão geralmente associadas a menores quantidades de informações textuais a serem lidas na tela, 0 quefacilita o trabal ho deleitura do usuário, além da existência de uma quantidade razoável de ligações hipertextuais, principal mentequando nos referimos às enciclopédias eletrônicas.

Com relação ao ato deler diretamente datela do computador, $\mathrm{N}$ ielsen (2000, p.101) relata que:

"A pesquisatem mostrado queler datela do computador écercade $25 \%$ mais lento do queler do papel. M esmo os usuários que desconhecem essas pesquisas sobre fatores humanos geralmente dizem que sentem desconforto ao lerem texto on-line. C omo resultado, as pessoas não querem ler muito texto das telas do computador".

Ainda, deacordo com N ielsen (2000, p.103), os problemas de legibilidade associados a ler a partir da tela do computador estão relacionados à resolução apresentada pelas mesmas. Embora existam telas com a resolução de 300 dpi, cuja qual idadeéequivalente aum texto impresso por uma impressora alaser ou jato detinta, as mesmas apresentam aindaum alto custo para aquisição. Segundo $\mathrm{N}$ ielsen (2000), telas com a resolução de 300 dpi serão comumente utilizadas por volta do ano 2007.

M esmo considerando quea qualidade das telas de computador disponíveis no mercado não apresentem qualidade satisfatória para o usuário, acreditamos queestenão é o único motivo que leve o usuário a imprimir o seu artigo de periódico para uma posterior leitura. 0 texto impresso apresenta facilidades que, no momento, ainda não estão disponibilizadas pelatecnologia deformauniversal. É possível para o usuário transportar o mesmo paraqualquer lugar independentemente da proximidade detomadas ou da disponibilidade de baterias. 0 pesquisador consegue facilmentefazer anotações no texto impresso com uma simples caneta. $\mathrm{N}$ o caso do extravio 


\section{Periódicos el etrônicos: considerações relativas à aceitação deste recurso pelos usuários}

do artigo, écompletamente viável acessar o si teondeestá hospedado o periódico e solicitar uma reimpressão, 0 que não seria tão viável na hipótese de o pesquisador estar fazendo a leitura do artigo ao ar livre com o seu laptop e viesse a perder o mesmo, devido ao custo deste dispositivo.

\section{CONSIDERAÇÕESFINAIS}

C om base no quefoi apresentado, podemos afirmar que de maneira al guma acreditamos que a plena aceitação dos periódicos eletrônicos esteja condenada em virtude de contingências tecnológicas. Estimamos que, dentro de um período de uma década, embora seja muitíssimo arriscado fazer exercícios defuturologia, teremos dispositivos portáteis de baixo custo que permitam 0 acesso a periódicos científicos eletrônicos eà sua leitura, de formatão transparentee simples, que mimetizem a contento o texto impresso em papel. Estes dispositivos devem possuir uma longa autonomia de operação, no caso de serem desplugados de umafonte de alimentação epossibilitarem também a conexão e o download wireless de bibliotecas digitais para a aquisição de uma variedade ilimitada de periódicos científicos ou qualquer outro tipo de texto que esteja no formato eletrônico. É possível fazer tal previsão a partir da observação do avanço constante da tecnologia e pelos novos dispositivos por ela disponibilizados a interval os cada vez mais curtos de tempo.

Transcendendo um pouco o estudo apenas dos periódicoscientíficos eletrônicos eolhando a publicação detextos no formato eletrônico, de uma maneira geral, tomaremos a liberdade de não concordar com a afirmação de $M$ artin apud $C$ hartier (1994, p.95), se levarmos em consideração a tecnologia disponível atualmente:

“O livro não exerce mais o poder queteve; elenão émais o mestredenossos raciocínios ou denossos sentimentos em face dos novos meios de informação e comunicação dos quais a partir deagoradispomos".

A situação acima só seria materializada em um mundo ondea tecnologia mimetizasse, ou seja, disponibilizasse todos os benefícios do meio impresso com os benefícios do meio eletrônico em um único dispositivo, de forma queusuários relevassem por completo o meio impresso, o que não acreditamos que vá ocorrer em médio prazo. O que supomos queiráacontecer seráa utilização paralelados dois meios.

A rtigo aceito para publicação em 25-11-2002

Ci. Inf., Brasília, v. 31, n. 3, p. 18-25, set./dez. 2002

\section{REFERÊNCIAS}

CH A RTIER, Roger. 0 s desafios da escrita. São Paulo : U nesp, 2002. A ordem dos livros. Brasília : U nB, 1995.

J O H N SO N , Steven. C ultura da interface. JorgeZahar. Rio deJ aneiro : 2001.

M A RC O N DES, C arlos H enrique; SA Y Ã O, Luís F ernando. I ntegração e interoperabilidade no acesso a recursos informacionais eletrônicos em C \& T : a proposta da Biblioteca D igital Brasileira. C iência da I nformação, Brasília, v. 30, n. 3, p. 24-33, set./ dez. 2001.

M A RC U SC H I, Luiz A ntônio. Linearização, cognição e referencia: 0 desafio do hipertexto. In: CO LÓ Q U IO DA A SSO CIAÇÃO LATIN O -A MERICAN A DE AN ALISTASDO DISCURSO , 4. Santiago, Chile, 1999.

MEA D O WS, A rthur J ack. A comunicação científica. Brasília: Briquet deL emos Livros, 1999.

N IELSEN , Jacob. Projetando websites: designing web usability. Rio de Janeiro : C ampus, 2001. 